\title{
Qual saldo, fermo e constante scoglio. Biografía y praxis. Dedicatoria en algunas dedicatorias latinas y en lengua vulgar de Giordano Bruno
}

Anna Laura Puliafito

Universidad de Basilea, Suiza

Traducción del italiano: María del Pilar Barenghi

Hablar de textos preliminares en el caso de Bruno significa tomar en consideración textos de diversa naturaleza, en prosa o verso, relacionados entre sí dada la gran relevancia que ellos poseen, generalmente, en cuanto instrumentos interpretativos de las obras a ellos ligadas. Las que presento ahora son algunas consideraciones generales sobre las características de las dedicatorias escritas por Giordano Bruno, consideradas en forma autónoma. $\mathrm{Y}$, puesto que se trata de primeras consideraciones, querría restringir este trabajo a los primeros escritos y a la producción en lengua vulgar. Examinaré, por lo tanto, las obras publicadas desde 1582 (año de publicación, en París, del De umbris idearum), hasta el año 1585 (año de publicación en Londres, de los Eroici furori). Cuatro años para Bruno de intensísimo trabajo, dedicados a la elaboración y proclamación de la "filosofía nolana". Y obras en su totalidad fuertemente ligadas entre sí, tanto en el plano textual como especulativo"

Siguiendo diversas modalidades, todos los textos considerados poseen dedicatorias escritas por el autor, excepto el Cantus circaeus $(1582)^{2}$. En este caso la epístola dedicatoria, bastante extensa, está firmada por Jacques Regnault, secretario del dedicatario (Enrico de Angoulême) y "curador" de la obra, como él mismo se presenta al lector ${ }^{3}$. Las otras obras en latín presentan muy sucintas dedicatorias a Enrique III, a Giovanni Moro -embajador de la Serenísima ante la corte francesay a Michel de Castelnau -embajador francés ante la corte de Inglaterra. Éstas aparecen anticipadas, excepto en el último caso, en el frontispicio ${ }^{4}$.

Por otro lado, las obras en lengua vulgar nos sitúan inmediatamente frente a algunas variantes tipológicas, tanto que la definición de algunos de estos textos en términos de "dedicatoria” exigen alguna consideración suplementaria. Para proceder ordenadamente recordaré brevemente los textos en cuestión:

Candelaio, "tragicomedia", publicada en 1582 y ofrecida "a la señora Morgana B";

La cena delle ceneri, el primero de los diálogos italianos, publicado en 1584, con una Proemiale epistola a Michel de Castelnau, señor de Mauvissière;

De la causa principio et uno, del mismo año 1584, también con una Proemial epistola a Michel de Castelnau;

De l'Infinito, universo et mondi, también de 1584, con una Proemial Epistola, al mismo señor de Mauvissière;

Spaccio de la bestia trionfante, el último diálogo de 1584, con una Epistola Esplicatoria a Philip Sidney; 
Cabala del cavallo pegaseo, publicado en 1585 y precedido de una Epistola Dedicatoria a don Sapatino, obispo de Casamarciano,

y, finalmente,

Degli Eroici furori, publicados también en 1585 y precedidos de un Argomento del Nolano sopra gli Eroici furori a Philip Sidney ${ }^{5}$.

Diversos elementos nos permiten reunir estos diferentes textos bajo el único rótulo de "dedicatoria", cuyos rasgos característicos y fundantes nos son presentados precisamente en el único entre ellos que lleva el explícito título de Epistola dedicatoria y que se encuentra en el principio de la Cábala.

El dedicatario de la obra es don Sapatino, obispo de Casamarciano, personaje considerado por algunos críticos totalmente imaginario, reconocido por otros como figura real ligada a la juventud de Bruno, quien habría alterado los datos biográficos, convirtiendo a un modesto párroco en el obispo de una imaginaria (¡ésta sí!) sede episcopal ${ }^{6}$. La epístola enuncia un principio fundamental de la praxis dedicatoria en general y bruniana en particular: es decir la necesaria correspondencia, sea por dignidad de grado, sea por afinidad de actividad o conocimiento entre el objeto ofrecido y el sujeto (la persona que lo recibe), el contenido de la obra y, por lo tanto, el dedicatario. Evocando el procedimiento, difundido en la época, de requerir para la dedicatoria un previo asentimiento de parte del posible dedicatario, a los fines de lograr parcial financiamiento de la propia actividad, Bruno enumera una larga serie de rechazos a su ofrecimiento ${ }^{7}$. Luego del rechazo de un caballero, de un minister verbi dei (un pastor reformado), de una primera y de una segunda dama, de una beguina, de un pedante, de un "versificador" identificados, que lamentan el escaso nivel del regalo, Bruno concluye:

Altri co l'altre raggioni mi parevan disposti a dovermene ringraziar o poco o niente, se io gli

l'avesse dedicato: et questo non senza caggione, perché (a dir il vero) ogni trattato, e con-

siderazione deve essere speso, dispensato e messo avanti a quel tale che è della suggetta professione o grado. ${ }^{?}$

El mismo principio es mencionado en De umbris, para el cual Bruno había escogido al rey de Francia, Enrique III, “tum nobilitate subiecti quod versatur, tum singularitate cui innititur, tum gravitate demonstrationis, qua communicatur" ${ }^{10}$. Y era fundamentalmente aquél el criterio que había llevado a la elección de la señora Morgana para el Candelaio. También en aquel caso el personaje femenino, real y alegórico, no era -o no sólo- la mujer inspiradora de amor, sino la "superlativamente erudita, sabia, bella y generosa” Morgana, a quien Bruno quería ofrecer el signo de su productividad intelectual en contra de los detractores de los años napolitanos ${ }^{11}$.

Antes de seguir, es necesario reducir explícitamente a todos los efectos al rol de dedicatoria: a las tres epístolas proemiales, a la epístola explicatoria y al argumento -en este orden- que acompañan a los demás diálogos.

Fundamento característico del acto dedicatorio - a partir de una constatación puramente empírica, pero verificable también en la tratadística contemporánea- ${ }^{12}$ es el acto del ofrecer el objeto a alguien, según los criterios de correspondencia ya mencionados. En la mayor parte de los casos, los motivos de correspondencia se manifiestan como elogio del destinatario. Se da naturalmente también el caso en el que se insiste, no en la excelencia del regalo, sino en la insuficiencia retórica del objeto para estar a la altura de la ilustre superioridad del personaje a quien está dirigido. Paralelamente el acto de entrega absoluta de quién ofrece, respecto de quién recibe, halla frecuentemente, en la humillación del oferente y en la respectiva exaltación de su buena disposición en el acto de donar, uno de los recursos retóricos más difundidos ${ }^{13}$. 
$\mathrm{El}$ acto de ofrecimiento es generalmente reconocible por medio de expresiones lingüísticas que denotan la ostensión del objeto-texto (he aqui, a vos presento, etc.) o la mención del acto de entrega, metafórico y literal (ofrezco, dono, consagro) ${ }^{14}$. Una variante de interés se fundamenta en el caso en el que el texto es "dirigido" al dedicatario, lo que pone de realce su función de lector privilegiado. La donación inmediata del objeto se proyecta, en general, sobre un efecto futuro, entendido como proyección de la fama, sublimada hasta hacerse inmortalidad ${ }^{15}$.

Ya en un primer examen todas las epístolas citadas y el argumento de 1585 resultan claramente divididas en dos momentos distintos: el del ofrecimiento de la obra y el de la exposición sintética, pero detallada, del argumento tratado. En cuatro de los cinco casos (queda excluido Spaccio) la división queda señalada también gráficamente en la paragrafatura de los argumentos propiamente dichos, encerrados entre las fórmulas de ofrecimiento y de despedida. En Spaccio la Epistola no presenta fórmulas de despedida y, después del ofrecimiento al dedicatario, la presentación de los argumentos continúa en forma compacta hasta el final. El nombre del dedicatario aparece siempre en la titulación del texto preliminar (veces anticipado también en el frontispicio, como ya hemos dicho). Todos los textos presentan fórmulas explícitas de ofrecimiento, como -es el caso de Cena- "He aquí, ilustre caballero", acomete allí sin rodeos y luego vuelto en "toma este retrato", "éste está dirigido a vos", "[mirad] el afecto con el que se dona", "[mirad] la mano que os lo ofrece", "a vos que con tanta magnificencia (...) a vos se consagra", reiteración significativa ésta, de la repetición "a vos os toca, a vos os dona" que se encontraba en la dedicatoria a Morgana ${ }^{16}$. La fórmula "a vos consagro" vuelve a aparecer en Causa, donde el texto bruniano está significado metafóricamente en la imagen del navío en la tempestad, y se repone en "he aquí aquella filosofía" y "os ofrezco con suma brevedad cinco diálogos" hasta la cláusula, sucesiva a la presentación de los argumentos "recibid por lo tanto con ánimo grato". También De l'Infinito presenta, antes que los Argumenti, una explicitación del ofrecimiento ("aquí os ofrezco mi contemplación”) repuesta en el cierre, implícitamente, en el acto de señalar la grandeza de ánimo no tanto en el recibir el regalo sino en el mostrarse, a su vez, generoso en el donar ("atendiendo que cuanto recibís de otros es testimonio de las ajenas virtudes, pero en tanto que lo hagáis a otro, es seña e indicio expreso de la vuestra"). Sin extenderme ahora demasiado en la lista de estas comparaciones, diré sólo que lo mismo vale también para Spaccio, que ya en el frontispicio enuncia la "consagración" a Sidney ("consagrado al caballero S."), a quien los diálogos son luego "presentados", esto es ofrecidos por Bruno como signo de agradecimiento ("Ciego quien no ve el sol [...] no permita el hado que yo deje signo de ingratitud (...) a vos presento"). En el caso de Eroici furori el ofrecimiento se concentra en la conclusión, posterior a la exposición del tema, en estrecha cohesión con el motivo de la correspondencia ("Estos son discursos, los que a ninguno le han parecido más convenientes que ser dirigidos y recomendados que a vos, señor excelente (...)"; "a vos por tanto se presentan, porque (...)"). En cuanto a este segundo criterio, el mismo asume una relevancia especial en la economía bruniana -como tendremos oportunidad de subrayar más adelante-articulándose en particular en los términos de deuda de agradecimiento de Bruno por los favores y el apoyo recibido. Por lo demás, la correspondencia deviene la enunciación de una afinidad de ingenio, que inscribe a los dedicatarios en el círculo de aquellos que tienen oídos para escuchar e instrumentos para comprender: la enciclopédica predisposición de don Sapatino y la sabiduría de Morgana se comparan con la "proximidad" de Bruno en términos de afinidad intelectual, disponibilidad meceanesca y "dignidad” moral del señor de Mauvissière y de Sidney. 
Como sostén, aun colateral, de las connotaciones de "dedicatoria" de los (peri)textos de los que nos estamos ocupando, se nota también un curioso error tipográfico que me ha sido posible comparar con seguridad en el caso de, al menos, dos ejemplares de la Cena y de Causa ${ }^{17}$. En ambos casos, un jefe de tipógrafos distraído, o tal vez demasiado aficionado y acostumbrado a la praxis textual y tipográfica, imprime en nítida cursiva como título corriente de la Epistola Proemiale, tanto sobre el recto como sobre el verso de las hojas, la expresión "Epístola Dedicatoria". Error fortuito o dictado por una costumbre que demasiado rápidamente impulsa a reconocer las dedicatorias en las epístolas antepuestas a los diálogos, esta frase deviene para nosotros una advertencia y un indicio inesperadamente claro del uso bastante libre que Bruno hace de la dedicatoria en terminos tipológicos, lo que no es nuevo ni sorprendente para su modo de componer y argumentar. Haciendo, en fin, uso de algunas metáforas canónicas y manteniéndose, en parte, ligado a las características estilísticas tradicionales de dedicatoria, en los diálogos, Bruno termina por definir de manera personal sus contenidos. En tal sentido logra dar un impulso particularmente incisivo a una manera de dedicar que quiere destacarse de la simple repetición de fórmulas de zalamería y adulación, reivindicando el texto de la obra por sobre el predominio de las ceremonias rituales. Una operación del género se halla auspiciada y esbozada en su desarrollo histórico no más de un lustro después de la publicación de los textos en lengua vulgar de Bruno, en el diálogo de Giovanni Fratta, donde, sobre la invitación de Porta "persona d'honorato grido, et ne' libri et ne’ le stampe”, Eugenio -epónimo protagonista del diálogo- afirma:

Porta -Di grazia trovate luogo homai a questi inquieti Dedicanti.

Eugenio -V'è un'arena nobilissima, dove possono spatiare, dietro a molti huomini per scientia immortali; si come si comprende da Cicerone, il quale con Epistola, ch'è spetie d'argomento, manda la sua Topica a Trebatio, e l'Oratore a Marco Bruto. Lo stesso hanno fatto Galeno, Oribasio, Dioscoride, et a' giorni nostri il Bembo, il Tomitano et altri infiniti, c'hanno incorporato detta Epistola con l'opera, parlando solamente a proposito per instruttione de' Lettori, et allontanandosi dalle ciance, vanità, adulazioni, come cose aliene dalla proposta materia, et con tal modo vengono per necessità lette le Dedicatorie, per essere incorporate nel soggetto, et vive la persona ivi nominata in perpetuo nella fronte del Libro. ${ }^{18}$ Como es conocido los diálogos se ligan y conectan en un programa muy articulado de reforma cultural y ética, verificable no sólo en la correspondencia, desarrollo, notas de contenido, sino localizable también en los textos preliminares, en la adopción, por ejemplo, de la metáfora de la semilla, de la cabeza, de la fuente.

Se lee en Causa:

Quivi come nel proprio seme si contiene et implica la moltitudine de le conclusioni della scienza naturale. Quindi deriva la intessitura, disposizione et ordine de le scientie speculative

(...). Prendete dumque con grato animo questo principio, questo uno, questo fonte, questo capo (...)

y, también, en el De l'Infinito:

Cossì, signor, gli santi numi disperdano da me que' tutti che ingiustamente m'odiano; cossì mi sia propicio sempre il mio Dio; cossì favorevoli mi sieno tutti governatori del nostro mondo; cossì gli astri mi faccian tale il seme al campo et il campo al seme, ch'appaia al mondo utile et glorioso frutto del mio lavoro, con risvegliar il spirto et aprir il sentimento a quei che sono privi di lume $(. . .)^{19}$

Predominante en los diálogos en lengua vulgar aparece, además, la idea de la "vicissitudine" y de la metamorfosis, de la transformación, modelo explicativo en el plano biográfico, histórico, ontológico y ético. El hombre-Bruno es un Mercurio positivo que sabe leer y desplegar en profundidad la imagen matemática del mundo realizada por Copérnico y desde ese punto parte para una revolución me- 
morable que moviliza desde el cielo y a él retorna, redefinendo el significado del ser como el de la virtud. Esta transformación se efectúa en la historia en tanto que fase específica de su movimiento cíclico y nace de la profunda decadencia de la que el s. $\mathrm{XVI}$, con sus guerras, sus prejuicios y su cultura libresca es un ejemplo particularmente incisivo. Tal transformación requiere, naturalmente, grandes sufrimientos y grandes empresas, sobre el plano colectivo, pero también sobre el plano personal. Y he aquí entonces que la atribulada biografía bruniana llega a sublimarse en la forma exterior de su misión "heroica". Es en este sentido en el que, tanto desde un punto de vista compositivo como teórico, se insertan las dedicatorias. Abandonando los modos sucintos y casi perentorios de la dedicatoria a Enrico III en De umbris y los convencionalmente retóricos de la Compendiosa architectura, Bruno arriba a las formas de la dedicatoria a Morgana, en la cual, en los tonos de un diálogo privado, ofrece y al mismo tiempo pide y confirma la protección de quien indirectamente puede hacerse portavoz de su mensaje, aceptando la vela que alumbrará las sombras de las ideas ${ }^{20}$. En un texto sui generis como su tragicomedia Bruno rechazaba ofrecer su "paraninfo" a una autoridad pública, civil o eclesiástica:

Et io a chi dedicarrò il mio Candelaio? A chi, o gran destino, ti piace ch'io intitoli il mio bel paranimfo, il mio bon corifeo? (...) A chi s'è voltato, dico io? a chi riguarda? a chi prende la mira? A sua Santità? No. A sua Maestà Cesarea? no. A sua Serenità? No. A sua Altezza, Signoria illustrissima e reverendissima? non, no. Per mia fé non è prencipe o cardinale, re, imperadore o pappa che mi levarrà questa candela di mano in questo sollennissimo offertorio. A voi tocca, a voi si dona; (...) in superlativo dotta, saggia, bella e generosa mia signora Morgana. ${ }^{21}$

En este caso la elección de Morgana tenía también un valor contrastativo: a ella "que goza en el seno de Abraham", Bruno se contrapone como el que "desesperadamente arde y chisporrotea", "académico de ninguna academia llamado el enojado", víctima de las polémicas que suscitan sus escritos ( las "sombras de las ideas" que espantan a las bestias y, como diablos dantescos, hacen permanecer a "los asnos lejos y atrás"). Seguro de su pensamiento, en la carta a Morgana, Bruno permanece en espera del día de la mutación. Se convence de que el "anochecer" esperado llega precisamente en el momento en que abandona la modalidad de la dedicatoria privada para asumir de manera totalmente nueva a aquella de la dedicatoria que llamaremos "pública" siguiendo la distinción de Fratta, que ya hacia el final del s. XVI anticipa en ciertos aspectos la conocida contraposición de Genette ${ }^{22}$ :

Eugenio - Ma tanto sia, ch'a Dio, a' Precettori, a i figliuoli, et à gli amici l'opere di propria elezzione si drizzavano; a i Principi per ordinario s'erano ricercati; ne' primi non v'era intentione, ò speranza di premio; ne' secondi si potevan prometter favore, et benefitio. Che poi alcuno resti protettore di quelle [i.e. opere], et le difenda dal livore, et morso de'maligni, questa è un'allegoria (...) et cagione mendicata per riputation de' libri, mostrando che quelli sieno meritevoli d'esser invidiati, overo si scrivono in adulazione de i pretensi difensori, dando loro ad intendere, che sieno di tanta stima, ch'l mondo tutto per timore gli riverisca.

Precisamente en este sentido, las dedicatorias a quien representa en Londres al cristiano rey de Francia, el embajador cuyos títulos detallados en siete líneas en el frontispicio de Cena ${ }^{23}$ están repetidos en la misma forma que en los títulos de las epístolas, se convierten en parte integrante de la programática metáfora del "cambio": Bruno proporciona una imagen de sí mismo retrayendo a un estado de cosas, pero ciertamente sirviéndose del mismo también para insistir sobre su propia misión histórica. Él parece responder en una manera del todo característica a la tópica de humillación-exaltación de dedicante y dedicatario. Ya la dedicatoria del Tringinta sigilli es muy elocuente en tal propósito: la demora de Castelneau ha visto el alumbramiento de aquel "parto de las Musas" y ha convertido "toto orbe seiunctam 
domum in domesticos lares" ${ }^{24}$. En el caso de la Cena Bruno insiste de una manera muy significativa sobre sus condiciones de vida y de trabajo, combinando los motivos tradicionales hasta proclamar al dedicatario su mecenas y protector, en un clima "donde los mercaderes sin conciencia ni fe, son fácilmente Cresos; y los virtuosos sin oro, no son difícilmente Diógenes" 25 .

El rol del Castelnau se presenta todavía más reforzado en el caso de Causa, la que Bruno inicia magnificando las virtudes del dedicatario por sus dotes de perseverancia y prontitud en las confrontaciones con todos en general, y del nolano en particular ${ }^{26}$.

Providencialmente salvada por la protección del Castelnau, Bruno está convencido de que su obra podrá entrar en el "sagrado templo de la fama", legando para toda la eternidad el favor concedido a su gloria:

a fin che conosca il mondo che questa generosa e divina prole inspirata da alta intelligneza, da regolato senso conceputa, e da Nolana Musa parturita, per voi non è morta entro le fasce, et oltre si promette vita: mentre questa terra col suo vivace dorso verrassi svoltando all'eterno aspetto de l'altre stelle lampegianti. ${ }^{27}$

El motivo de la gratitud debida a la protección se enlaza finalmente a otro topos de la reflexión bruniana, y esto es el programático convencimiento de que no todos puedan ni deban estar en condiciones de oír su mensaje de reforma. Como el furor heroico es experiencia de unos pocos bienaventurados, así, por definición, no todos están en condiciones de escuchar la densa trama de los textos brunianos, plenos de contenidos densos y estratificados que resultan comprensible sólo a pocos.

La pertenencia por parte del mecenas al restringido círculo de aquellos que están -al menos en parte- en grado de entender (como queda manifiesto por su apoyo económico y social), pertenencia que, como hemos señalado, constituye perjudicialmente uno de los criterios formales de la elección del dedicatario, hace de esta forma, que se cree una clase de concatenación típica entre inspiración divina, musa inspiradora, obra y protección recibida: a través del motivo autobiográfico, el apoyo ofrecido al libro se derrama sobre toda la actividad especulativa de Bruno, siempre presentada en términos de oposición a la ignorancia corriente respecto de aquellos que se creen sabios. Las dificultades de Bruno se convierten al mismo tiempo en medida de la fuerza y de la constancia del protector, y los términos de la fama ofrecida a él van a inscribirse en la metáfora del nuevo día.

En Spaccio della bestia trionfante, ofrecido a Philip Sidney, gran poeta de la corte de la reina Isabel I, el procedimiento cumple también otra finalidad. Un primer signo puede ser individualizado ya en el frontispicio, en el cual el nombre de Bruno no aparece en la posición generalmente reservada al autor, sino que aparece incorporada en una lista-siempre invariable desde el punto de vista de morfosintáctico- que partiendo de Júpiter, inspirador de la acción, concluye precisamente con la consagración de la obra al dedicatario:

Spaccio / de la bestia trion- / fante, proposto da Giove, / Effettuato dal conseglo, Re- / velato da

Mercurio, Recitato da So-/ phia, Udito da Saulino, Regi-/ strato dal Nolano. Diviso / in tre

dialoghi, subdi- / visi in tre parti. / Consecrato al molto illustre / et eccellente Cavalliero Sig.

/ Philippo Sidneo. ${ }^{28}$

Se trata de un variante incisiva del fenómeno al que se ha hecho referencia más arriba y del nexo creado por Bruno entre inspiración y realización de la obra, causa divina y protección humana.

Llegamos así, por límites de tiempo y espacio antes que por agotamiento del tema, a los Eroici furori. La peculiaridad de la composición implica aquí también lo que creo poder llamar texto de dedicatoria, esto es el Argomento del Nolano sopra gli Eroici furori. Después de la concisa presentación de los motivos para los cuales "la 
última finalidad de esta tesitura fue y es la de aportar la contemplación divina, y poner delante de los ojos y de los oídos ajenos furores, no vulgares, pero sí de heroicos amores", y de la compleja presentación de los diálogos particulares, Bruno presenta en la conclusión, los motivos característicos de la dedicatoria, que el autor compendia una última vez enunciando las correlaciones y la deuda de gratitud, subrayando la profunda ligazón y la afinidad intelectual entre él, el autor, y Sidney, el dedicatario. No obstante no deja de introducir una fundamental diferencia entre los textos poéticos contenidos en los diálogos y la filosofía que en ellos se muestra. Si los primeros tienen aún la necesidad de la protección del Sidney poeta, la filosofía puede mostrarse desnuda a los ojos del lector dotado de ingenio puro, como precisamente es aquél a quien se ofrece y presenta el último de los diálogos vulgares ${ }^{29}$.

El s. XVI conoce un ceremonial dedicatorio muy preciso y definido en sus partes. Siguiendo la práctica de su tiempo Bruno concede extenso espacio a la dedicatoria, de la que, en los diálogos italianos, mantiene algunas características formales profundizando, no obstante, el significado: la dedicatoria hace de prólogo y llave, y la epístola proemial y explicatoria se connota como dedicatoria, de la que mantiene en formas diversas las características estilísticas y las metáforas canónicas. En el volumen que contiene los tres poemas latinos de 1591, el título corriente reconocerá explícitamente a la dedicatoria la función que ya desde las primeras obras le corresponde: Epistola dedicatoria et clavis. ${ }^{30}$

Por el gran espacio que la autobiografía asume en la concepción bruniana de la historia intelectual y, por otra parte, por los fuertes ecos que ella necesariamente tiene en los textos de dedicatoria, también estos últimos, en cuanto expresión de un mecenazgo garante de la nueva filosofía, terminan por ser introducidos sistemáticamente en el modelo de la "transformación" sobre el que se mueve rítmicamente el profético afirmarse de la filosofía bruniana, en el proceder incesante de la "vicissitudo" natural.

\footnotetext{
Notas

${ }^{1}$ Iordanus Brunus, Nolanus: De umbris idearum, (...), Ad Henricum III. Serenis. Gallor. Polonorúmque Regem, \& c., Parisiis, Apud Ægidium Gorbinum, sub insigne Spei, è regione gymnasij Cameracensis, 1582. Cum privilegio Regis (ed. cons. G. Bruno, De umbris idearum, a cura di R. Sturlese, Premessa di E. Garin, Firenze, Olschki, 1991).

${ }^{2}$ Philothei Iordani Bruni Nolani Cantus circaeus (...), Ad altissimum principem Henricum d'Angoulesme magnum Galliarum Priorem, in Provincia Regis locumtenentem, \& c., Parisiis, Apud Ægidium Gillium, via S. Ioannis Lateranensis, sub trium coronarum signo, 1582 (ed. cons. in Eiusd. Opera latine conscripta. Faksimile-Neudruck der Ausgabe von Fiorentino, Tocco und anderen, Neapel-Florenz 1879-1891, Bd. II 1: De Umbris idearum. Ars memoriae. Cantus circaeus, Stuttgard-Bad Cannstatt, F. Frommann Verlag G. Holzboog, 1961. La dedicatoria del Cantus se lee aquí en las pp. 181-83).

${ }^{3}$ Cfr. Bruni Cantus, cit., p. 182. Sobre la función de la obra y sobre las posibles ingerencias de Bruno en la redacción del texto dedicatorio cfr. V. Perrone Compagni, "Minime occultum chaos". La magia riordinatrice nel "Cantus Circaeus", "Bruniana \& Campanelliana", a. VI (2000/2) pp. 282-97, p. 295. Sobre el significado del ofrecimiento del Cantus y la rela-
} 
ción con Enrique III, vd. también P. Sabbatino, Nei luoghi di Circe. L’Asino di Machiavelli e il Cantus Circaeus di Bruno, in AA.VV., Cultura e scrittura in Machiavelli. Atti del convegno Firenze-Pisa (27-30 ottobre 1997), Roma, Salerno, 1997, pp. 553-96; y S. Ricci, Giordano Bruno nell'Europa del Cinquecento, Roma, Salerno, 2000.

${ }^{4}$ Philotheus Iordanus Brunus Nolanus, De compendiosa architectura, \& complemento artis Lullij, Ad illustrissimum D. D. Ioannem Morum pro Serenissima Venetorum R. P. apud Christianissimum Gallorum \& Polonorum regem, legatum, Parisiis, Apud Ægidium Gorbinum, sub insigne Spei, propè Colegium Cameracense, 1582 (ahora en Bruni Opera latine conscripta, cit., vol. II 2, dedicatoria en p. 6); Philothei Iordani Bruni Nolani Explicatio triginta sigillorum (...) Quibus adiectus est Sigillus Sigillorum, s.n.t. (ahora en Eisd. Opera latine conscripta, cit., vol. II 2, dedicatoria en p. 75). Conjuntamente con la Esplicatio y el Sigillus se publica la Ars reminiscendi (Eiusd. Recens et completa ars reminiscendi et in phantastico campo exarandi, ad plurimas in triginta sigillis inquirendi, disponendi atque retinendi implicitas novas rationes et artes introductoria, s.n.t. (ahora en Eiusd.Opera latine conscripta, cit., vol. II 2 pp. 69-72); en algunos ejemplares de la Explicatio se encuentra inserta una epístola dirigida por Bruno al Vicecanciller de la universidad de Oxford (cfr. ivi, pp. 76-78); por su carácter apologético se trata, no obstante, de una introducción más que de una dedicatoria en sentido propio. Cfr. Giordano Bruno. Gli anni napoletani e la 'peregrinatio' europea. Immagini. Testi. Documenti, a cura di E. Canone, Cassino, Università degli Studi, 1992, p. 91, que ofrece también la reproducción del frontispicio.

${ }^{5}$ Giordano Bruno, Nolano: De gl'heroici furori (...), Parigi, Appresso Antonio Baio [ma Londra, J. Charlewood], l'Anno 1585; La cena de le Ceneri. Descritta in cinque dialogi, per quattro interlocutori, Con tre considerationi, Circa doi suggettj, (...), s.l., s.e., [ma Londra, J. Charlewood], 1584; Candelaio. Comedia del Bruno Nolano Achademico di nulla Achademia, detto il fastidito, (...), In Pariggi, Appresso Guglelmo Giuliano. Al segno dell'Amicizia, 1582 (ahora también en Id., Evres complètes, I: Chandelier, introduction philologique de G. Aquilecchia. Texte établie par G. Aquilecchia. Préface de G. Bárberi Squarotti. Traduction de Y. Hersant, Paris, Les Belles Lettres, 1993, dedicatoria en pp. 9-15; para la traducción en castellano cfr. Id., Candelero. Traducción integral, estudio preliminar y notas: Sforza, N. H., Facultad de Filosofía y Letras, Buenos Aires, 2002); Id., De la causa, principio, et Uno. A' L'Illustrissimo Signor di Mauvissiero, Stampato in Venetia, s.e. [ma Londra, J. Charlewood], 1584; Id., De l'infinito, universo et Mondi. All'illustrissimo Signor di Mauvissiero, Stampato in Venetia, s.e. [ma Londra, J. Charlewood], 1584; Spaccio de la bestia trionfante (...), Consecrato al molto illustre et eccellente cavalliero Sig. Philippo Sidneo, Stampato in Parigi, s.e. [ma Londra, J. Charlewood], 1584; Cabala del cavallo pegaseo. Con l'aggiunta dell'Asino cillenico. Descritta dal Nolano: dedicata al Vescovo di Casamarciano, Parigi, Appresso Antonio Baio [ma Londra, J. Charlewood], Anno 1585. Más que en la edición GentileAquilecchia (Id., Dialoghi italiani. Nuovamente ristampati con note da G. Gentile. Terza edizione a cura di G. Aquilecchia, Firenze, Sansoni, 1958, voll. 2, ristampa Firenze, Sansoni, 1985), el texto de la comedia y de todos los diálogos en lengua vulgar se leen también ahora en Id., Opere 
italiane. Ristampa delle cinquecentine, a cura di E. Canone, Firenze, Olschki, 1999, voll. 4 (de ahora en adelante OP); sólo los diálogos se leen además en Id., Dialoghi filosofici italiani, a cura e con un saggio introduttivo di M. Cilberto, Milano, Arnoldo Mondadori, 2000 (DFI). Para hacer más ágil la consulta, si no se indica expresamente de ahora en más las citaciones harán referencia a esta última edición, indicada por la sigla (DFI). Para el censo de las ediciones brunianas del s. XVI cfr. R. Sturlese, Bibliografia, censimento e storia delle antiche stampe di Giordano Bruno, Firenze, Olschki, 1987.

${ }^{6}$ Se trata de un personaje imaginario, por ejemplo, según DFI, p. 1292, n. 2; de otra opinión, por ejemplo, M. A. Granada, que en su traducción española del diálogo se refiere a un personaje real, "modesto clérigo de la parroquia de Santa Prima desde 1576 (...)”; pero añade: "pero los pomposos títulos que en broma se le adjudican son falsos -Casamarciano nunca fue sede episcopal-”, cfr. G. Bruno, Cábala del Caballo Pegaso. Traducción y notas de M. A. Granada, Madrid, Alianza Editorial, 1990, p. 69 , n. 1 .

${ }^{7}$ La serie corresponde a la lista negativa que se halla en la dedicatoria a Morgana, cuando el autor mismo renuncia a ofrecerles el escrito a algunos posibles destinatarios.

${ }^{8}$ Sobre el significado de "versificatore", cfr. Spaccio, DFI, p. 609, como lo destacan Granada en Bruno, Cábala, cit., n. 5 p. 71 y Ordine, N.: $L a$ cabala dell'asino. Asinità e conoscenza in Giordano Bruno, Liguori, Napoli, 1987, pp. 152 y siguientes.

${ }^{9}$ DFI, p. 676 ("Otros me parecían dispuestos con otras razones a quererme dar gracias poco o nada en el caso de que se lo hubiera dedicado y no sin razón, porque a decir verdad todo tratado y consideración debe ser enviado, concedido y presentado a quien es de la profesión o grado objeto de examen", G. Bruno, Cábala, cit., p. 72).

${ }^{10}$ Bruno, De umbris, cit., p. 5. Igualmente en la sucinta dedicatoria del Compendiosa architectura a Giovanni Moro en que la elección del destinatario venía justificada con una similitud hiperbólica obra-gema (cfr. en Bruni Opera latine conscripta, cit., vol. II 2 p. 5). Sobre la correspondencia obra-dedicatario cfr. Della dedicatione de' libri (...). Diálogo del sig. Giovanni Fratta, nobile veronese, Con privilegio, In Venetia, Appresso Giorgio Angelieri, 1590, c. 19; señalado en C. Lucas, Vers une nouvelle image de l'écrivain: "Della dedicatione de' libri" de Giovanni Fratta, en AA.VV., L'Ecrivain face à son public en France et en Italie à la renaissance. Actes du Colloque International de Tours (4-6 Décembre 1986). Études réunies et présentées par Ch. A. Fiorato et J. C. Margolin, Paris, Vrin, 1989, pp. 85-104.

${ }^{11}$ Cfr. Candelaio en Bruno, Euvres. I, cit., p. 11. Sobre las posibles identidades de Morgana cfr. A. Gareffi, L'identità della Signora Morgana, en AA.VV., Teatri barocchi. Tragedie, commedie, pastorali nella drammaturgia europea fra '500 e '600, a cura di S. Carandini, Roma, Bulzoni, 2000, pp. 359-72.

${ }^{12}$ Cfr., por ejemplo, el ya citado Fratta, que reconstruye la genealogía de la dedicatoria como regalo, desde la antigüedad en Della dedicatione, cit., c. $17 v$.

${ }^{13}$ Para un panorama sobre las características compositivas de la dedicatoria de "ancien régime" cfr. I margini del libro. Indagine teorica e storica sui testi 
di dedica. Atti del convegno internazionale di studi Basilea, 21-23 novembre 2002. A cura di M.A.Terzoli, Roma-Padova, Antenore, 2004. El volumen contiene también la versión más amplia, en italiano, del presente ensayo (A proposito di alcune dediche di Giordano Bruno, pp. 117-139).

${ }^{14}$ Cfr. Della dedicatione, cit., c. $20 r$ : "(...) i Greci, come primi autori in questa materia, che siano capitati alle nostre mani mentre dirizzavano l'opere loro ad alcuno, chiamavano ragionare, et i Latini mandare, et noi dopo l'uso delle Stampe, con voce pregnanti di vanità diciamo donare, dedicare et consacrare"; cfr. también S. Battaglia, Grande Dizionario della Lingua Italiana, Torino, UTET, 1961 siguientes, s. v. 'consacrare', que cita Marino (G. B. Marino, Dicerie sacre. La strage degli innocenti, a cura di G. Pozzi, Torino, Einaudi, 1960, pp. 69-70): “Alla Immortalità / di Paolo V, Pontefice (...) / questo / picciolo testimonio di reverente affetto / insieme con tutte l'altre sue fatiche / la divota penna del Cavalier Marino / umilmente, prontamente, meritamente / dona, dedica, consacra”.

${ }^{15}$ Cfr. Della dedicatione, cit., c. $23 r$; también hallan interesantes consideraciones, por ejemplo, en las dedicatorias de Lope de Vega, parcialmente analizadas en T. E. Case, Las dedicatorias de 'Partes' XIII-XX de Lope de Vega, Madrid, Castalia, 1975, pp. 21 siguientes.

${ }^{16}$ Candelaio, en Bruno, Euvres. I, cit., p. 11.

${ }^{17}$ Los ejemplares en cuestión son conservados en la biblioteca Trivulziana de Milano reproducidos anastáticamente a cargo de E. Canone. La misma frase se encuentra también en los ejemplares conservados en Amsterdam, en la Biblioteca Filosófica Hermética J R Ritman -debo el hallazgo a la generosa disponibilidad del Dra. Cis Van Heertum que agradezco de corazón-. Sería interesante proceder a la verificación de otros ejemplares disponibles.

${ }^{18}$ Della dedicatione, cit. cc. $22 v-23 r$.

${ }^{19}$ DFI, cit., pp. 174; 302 (“Así, señor, los santos números alejen de mí a todos los que injustamente me odian; así me sea siempre propicio siempre mi Dios; así me sean favorables todos los que gobiernan este mundo; así los astros me adecuen la semilla al campo y el campo a la semilla, de modo que aparezca al mundo útil y glorioso el fruto de mi trabajo, despertando el espíritu y abriendo el sentido a quienes están privados de luz[...]", G. Bruno, Sobre el infinito universo y los mundos. Trad. prólogo y notas Angel J. Capelletti, Buenos Aires, Hispamérica, 1984, p 44). En el De l'Infinito la misma imagen es utilizada en el espacio propio del argumento:: "Altri molti sono i degni et onorati frutti, che da questi arbori si raccoglieno; altre le mèsse preciose e desiderabili, che da questo seme sparso riportar si possono: le quali (...) lasciamo comprendere dal giudizio di quei che possono comprendere e giudicare, li quali da per se medesimi potranno facilmente a questi posti fondamenti sopra edificar l'intiero edificio de la nostra filosofia: gli cui membri, se cossò piacerà a chi ne governa e muove, e se l'incominciata impresa non ne verrà interrotta, ridurremo alla tanto bramata perfezzione; a fine che quello che è seminato ne gli dialogi De la Causa, principio et uno, nato per questi De l'infinito, universo e mondi, per altri germogli, per altri cresca, per altri si mature, per altri mediante una rara mietitura ne addite, e per quanto è possibile ne contente (...)" (ivi, p. 318).

20 “(...) eccovi la candela che vi vien porgiuta per questo Candelaio che da me si parte, la qual in questo paese ove mi trovo potrà chiarir alquanto 
certe Ombre dell'idee, le quali invero spaventano le bestie, e come si fussero diavoli danteschi, fan rimaner gli asini lungi a dietro; et in cotesta patria ove voi siete, potrà far contemplar l'animo mio a molti, e fargli vedere che non è al tutto smesso", Candelaio, in Bruno, Euvres. I, cit., pp. 11-13 (“(...) aquí està la candela que os es ofrecida por este Candelero que parte desde mí, la cual en este país donde me encuentro podrà aclarar ciertas Sombras de las ideas que en verdad asustan a las bestias y, como si fueran diablos dantescos, hacen permanecer a los asnos bien atrás; y en esta patria, donde vos estáis, podrá hacer contemplar mi alma a muchos, y hacerles ver que no ha sido del todo abandonada”, Id., Candelero, cit., p. 7). ${ }^{21}$ Candelaio, in Bruno, Euvres. I, cit., pp. 9-11 (“'Y yo a quién dedicaré mi Candelero? ¿A quién, oh, gran destino, te gusta que yo dedique mi bello rufián, mi buen corifeo? (...) ¿̇A quién se ha girado, -digo yo-, a quién mira, a quién busca? ¿A su Santitad? No. ¿A Su Majestad Cesárea? No. ¿A Su Serenidad? No. ¿A Su Alteza, Señoría Ilustrísima y reverendisima? No, no. Por mi fe, no existe ni príncipe, o cardenal, rey, o emperador o Papa que me quite esta candela de la mano, en este solemnísimo ofertorio. A vos toca, a vos se dona (...) superlativamente docta, sabia, bella y generosa señora mía Morgana”, Candelero, cit. p. 7)

${ }^{22}$ Genette, G. Seuils, Paris, Éditions du Seuil, 1987, p. 123 (trad. it. Soglie. I dintorni del testo.) A cura di C M Cederna, Torino, Einaudi, 1989; Della dedicatione, cit., cc. $18 v-19 r$.

${ }^{23}$ La dedicatoria está en cambio sólo brevemente señalada en los frontispicios de De la causa y del De l'Infinito (en ambos casos, con variante ortográfica, "all'illustrissimo signor di Mauvissiero").

${ }^{24}$ Bruni Explicatio, in Bruni Opera latine conscripta, cit., vol. II 2 p. 75.

${ }^{25}$ Cena, DFI, p. 16 y n. 78. Diogene Laercio racconta (Vite, VI 32) que el único favor pedido por Diógenes a Alejandro Magno fue correrse, así el sol podía de nuevo calentarlo (cfr. DFI, p. 976, n. 78).

${ }^{26}$ De la causa, DFI, p. 163.

${ }^{27}$ Ivi, p. 165. Letra normal de la autora. Con la promesa de inmortalidad se cierra la dedicatoria del De l'Infinito, una inmortalidad entendida como efecto no de beneficios recibidos, sino de aquellos hechos: "E vi ricordo quel che so che non bisogna ricordarvi, che non potrete al fine esser tanto stimato dal mondo e gratificato da Dio per essere amato e rispettato dai prìncipi qualsivoglia grandi della terra: quanto per amare, difendere e conservare un di simili. Perché non è cosa che quelli che con la fortuna vi son superiori, possono fare a voi, che molti di lor superate con la virtude, lo che possa durare più che gli vostri pareti e tapezzarie; ma tal cosa voi possete fare ad altri, che facilmente vegna scritta nel libro dell'eternitade, o sia quello che si vede in terra o sia quell'altro che si crede in cielo: atteso che quanto che ricevete da altri è testimonio de l'altrui virtude, ma il tanto che fate ad altro, è segno et indizio espresso de la vostra", De l’infinito, DFI, p. 319.

${ }^{28}$ Spaccio, DFI, p. 457, letra normal de la autora.

29 "Questi son que' discorsi, gli quali a nessuno son parsi più convenevoli ad essere addirizzati e raccomandati che a voi, Signor eccellente: a fin che io non vegna a fare, come penso aver fatto alcuna volta per poca advertenza, e molti altri fanno quasi per ordinario, come colui che presenta la lira ad un sordo, et il specchio ad un cieco. A voi dumque si presentano, perché l'Italiano raggioni con chi l'intende; gli versi sien sotto la censura e 
protezzion d'un poeta; la filosofia si mostre ignuda ad un sì terso ingegno come il vostro; le cose eroiche siano addirizzate ad un eroico e generoso animo, di qual vi mostrate dotato; gli officii s'offrano ad un suggetto sì grato, e gli ossequii ad un signor talmente degno qualmente vi siete manifestato per sempre", Eroici furori, DFI, pp. 772-73. Para la interpretación del pasaje referido a la filosofía hago referencia a las notas de M. A. Granada y a la traducción francesa en la edición París 1999 (en G. Bruno, Evres complètes, VII: Des fureurs hérö̈ques. Introductions et notes de M. A. Granada. Traduction de P.-H. Michel revue par Y. Hersant, Paris, Les Belles Lettres, 1999, pp. il-1 y n.).

${ }^{30}$ Iordani Bruni, N. De monade numero et figura liber consequens quinque De minimo magno et mensura. Item De innumerabilibus, immenso et infigurabili; seu de universo et mundis libri octo. Ad Illustrissimum et reverendissimum principem Henricum Julium Brunsvicensium et Lunaeburgensium ducem, Halberstadensium Episcopum, etc., Francofurti, Apud Joan. Wechelium et Petrum Fischerum consortes, 1591 (reimpress. anast. a cargo de E. Canone, La Spezia, Agorà, 2000). En la edición a cargo de Fiorentino, la dedicatoria está antepuesta al De immenso (cfr. Bruni Opera latine conscripta, cit., vol. I 1-2 pp. 193-99). 